\title{
Management of Frontal Bone Fracture in a Tertiary Neurosurgical Care Center-A Retrospective Study
}

\author{
Rakshith Srinivasa $^{1}$ Sunil V. Furtado ${ }^{10}$ Tanvy Sansgiri ${ }^{2}$ Kuldeep Vala $^{1}$ \\ ${ }^{1}$ Department of Neurosurgery, MS Ramaiah Medical College and \\ Hospital, Bangalore, Karnataka, India \\ 2 Department of Oral and Maxillo-facial Surgery, MS Ramaiah Dental \\ College and Hospital, Bangalore, Karnataka, India \\ Address for correspondence Sunil V. Furtado, MBBS, MS, MCh, DNB, \\ Department of Neurosurgery, MS Ramaiah Medical College and \\ Hospital, Bengaluru 560054, Karnataka, India \\ (e-mail: sunilvf@gmail.com).
}

J Neurosci Rural Pract 2022;13:60-66.

\begin{abstract}
Keywords

- frontal bone fracture

- frontal sinus fracture

- CSF leak

- cranialization
\end{abstract}

Objective We present our experience in the management of frontal bone fractures using the previously described radiologic classification of frontal bone fractures.

Methodology A retrospective study was conducted, which reviewed the medical records and computed tomographic (CT) scan images of patients with frontal bone fracture from January 2016 to February 2019. Patients with complete medical records and a follow-up of minimum 1 year were included in the study. Demographic details, mechanism of injury, associated intracranial injuries, maxillofacial fractures, management, and complications were analyzed. CT scan images were used to classify the frontal bone fractures using the novel classification given by Garg et al (2014). The indications for surgical treatment were inner table frontal sinus fracture with cerebrospinal fluid (CSF) leak, intracranial hematoma with significant mass effect requiring surgical evacuation, and outer table comminuted fracture that is either causing nasofrontal duct obstruction or for cosmetic purpose.

Results A total of 55 patients were included in the study. Road traffic accidents as the commonest cause of frontal bone fractures. The most common fracture pattern was type 1 followed by type 5 and depth B followed by depth A. Four patients presented with CSF rhinorrhea. CSF rhinorrhea was more frequent with fracture extension to the skull base (depth B, C, D), which was statistically significant $(p<0.001)$.

Conclusion Frontal bone fracture management has to be tailor-made for each patient based on the extent of the fracture, presence of CSF leak, and associated intracranial and maxillofacial injuries.

\section{Introduction}

Frontal bone fractures constitute 5 to $15 \%$ of the maxillofacial fractures. ${ }^{1}$ Due to its anatomic location and its close prox- imity to the vital structures like the brain, skull base, and orbit, these fractures can cause devastating sequelae if managed inadequately. Enormous amount of force is needed published online January 5, 2022
DOI https://doi.org/ 10.1055/s-0041-1740615. ISSN 0976-3147.

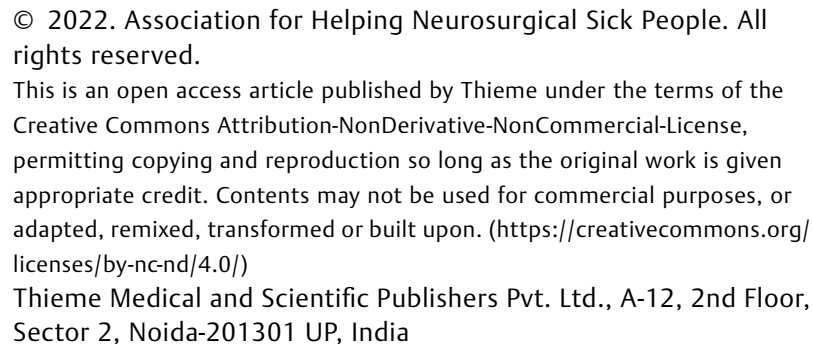

(c) 2022. Association for Helping Neurosurgical Sick People. All rights reserved.

This is an open access article published by Thieme under the terms of the Creative Commons Attribution-NonDerivative-NonCommercial-License, permitting copying and reproduction so long as the original work is given appropriate credit. Contents may not be used for commercial purposes, or adapted, remixed, transformed or built upon. (https://creativecommons.org/ licenses/by-nc-nd/4.0/)

Thieme Medical and Scientific Publishers Pvt. Ltd., A-12, 2nd Floor, Sector 2, Noida-201301 UP, India 
to fracture the thick frontal bone and they are mostly caused by anterior blunt trauma. ${ }^{2}$ The most common etiology is high velocity road traffic accidents (RTA) involving high energy impact to the upper face, followed by sports, assaults, falls from height, and penetrating trauma from industrial accidents. $^{2-5}$

The frontal sinus injuries are associated with frontal bone fractures with varying degree of severity. ${ }^{6}$ It is absent at birth and at around 2 years of age it begins to form by the invasion of the anterior ethmoid air cells into the frontal bone and reaches its adult size by 15 years. The frontal sinus drains via the nasofrontal duct (NFD) that is located medially. ${ }^{5,6}$ Frontal sinus fractures can present either as isolated outer table fracture or combined outer and inner table fractures and/or NFD injuries. Isolated inner table fractures are uncommon. ${ }^{7}$ The novel classification by Garg et $\mathrm{al}^{8}$ classifies frontal bone fractures depending upon nonvertical and vertical trajectories into five types and depending upon the depth of skull base extension into four types. This classification is purely based on radiological findings. The management of frontal bone fractures depends on the site and extent of injury. Concomitant injuries also play an important role in treatment planning. Management of frontal bone fracture is influenced by the clinical condition of the patient, as assessed by Glasgow Coma Scale (GCS), presence or absence of cerebrospinal fluid (CSF) rhinorrhea, presence of associated intracranial injuries or bleedings with mass effect requiring surgical intervention.

\section{Materials and Methods}

A retrospective study was conducted in the department of neurosurgery in tertiary care center, Bengaluru. The medical records and computed tomographic (CT) scan images of patients with frontal bone fracture who reported to the department between January 2016 and February 2019, with complete medical records and a follow-up of 1 year, were included in the study. Demographic details, mechanism of injury, associated intracranial injuries, CSF rhinorrhea (leak), and GCS at the time of presentation, associated maxillofacial fractures, the treatment provided, and postoperative complications were recorded. CT scan images were used to classify the frontal bone fractures using the novel classification given by Garg et al. ${ }^{8}$ Frontal bone fractures were primarily distinguished as having a nonvertical or vertical trajectory. Type 1 fractures were defined as comminuted fractures of the frontal sinus without a vertical trajectory, type 2 fractures are vertical fractures involving the orbit but not the frontal sinus, type 3 fractures are vertical fractures involving the frontal bone and sinus but not the orbit, type 4 fractures are both the frontal sinus and the ipsilateral orbit, and type 5 fractures cross the midline of face and involve the frontal sinus and contralateral or both orbits as shown in the illustration figure $(-$ Fig. 1) and CT scan images (-Fig. 2). The depth of skull base extension was also classified for all fractures. Depth $A$ is involvement of the frontal bone without extension to skull base, and depth $B$ is characterized as extension to anterior cranial floor (orbital

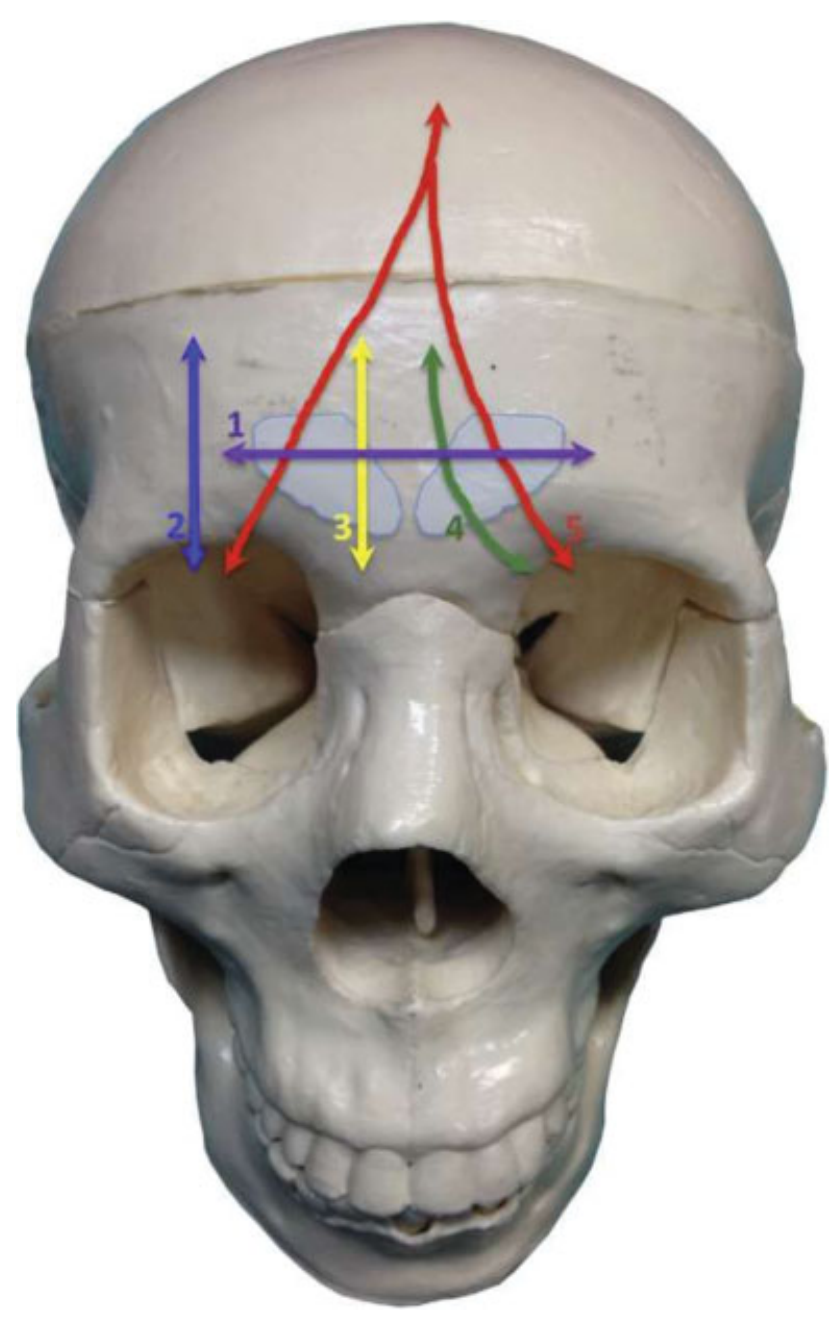

Fig. 1 Illustrative figure: Frontal bone fracture types. Type 1 fractures are isolated to the frontal sinus without a vertical trajectory (purple). Type 2 fractures are vertically oriented and extended into the orbit but not the frontal sinus (blue). Type 3 fractures are vertically oriented and extended into the frontal sinus but not the orbit (yellow). Type 4 fractures are vertically oriented and extended into ipsilateral frontal sinus and orbit (green). Type 5 fractures extend into the frontal sinus and the orbit on both sides of the face or the contralateral side of the face (red). Image courtesy: Garg et al. ${ }^{8}$

roof, fovea ethmoidalis, cribriform plate). Depth $\mathrm{C}$ fractures extend into middle cranial fossa (sella, sphenoid sinus, carotid canal, optic chiasm sulcus), and depth D fractures involve posterior fossa (clivus, petromastoid temporal bone, petrosal segment of the carotid canal), as shown in illustrative figure (-Fig. 3 ) and CT image (-Fig. 4).

Patients' GCS score at time of presentation, presence or absence of CSF leak, and presence or absence of associated intracranial injuries were noted. Patients with nondisplaced frontal sinus fractures of the outer and/or inner table were managed depending on their neurological status. If there was no CSF leak and/or brain injury and did not require craniotomy and hematoma evacuation and with no NFD injuries, such cases were treated conservatively. Patients with isolated displaced outer table fracture with associated maxillofacial fractures and no brain injury, with NFD obstruction, were managed with ORIF with the preservation of the frontal 


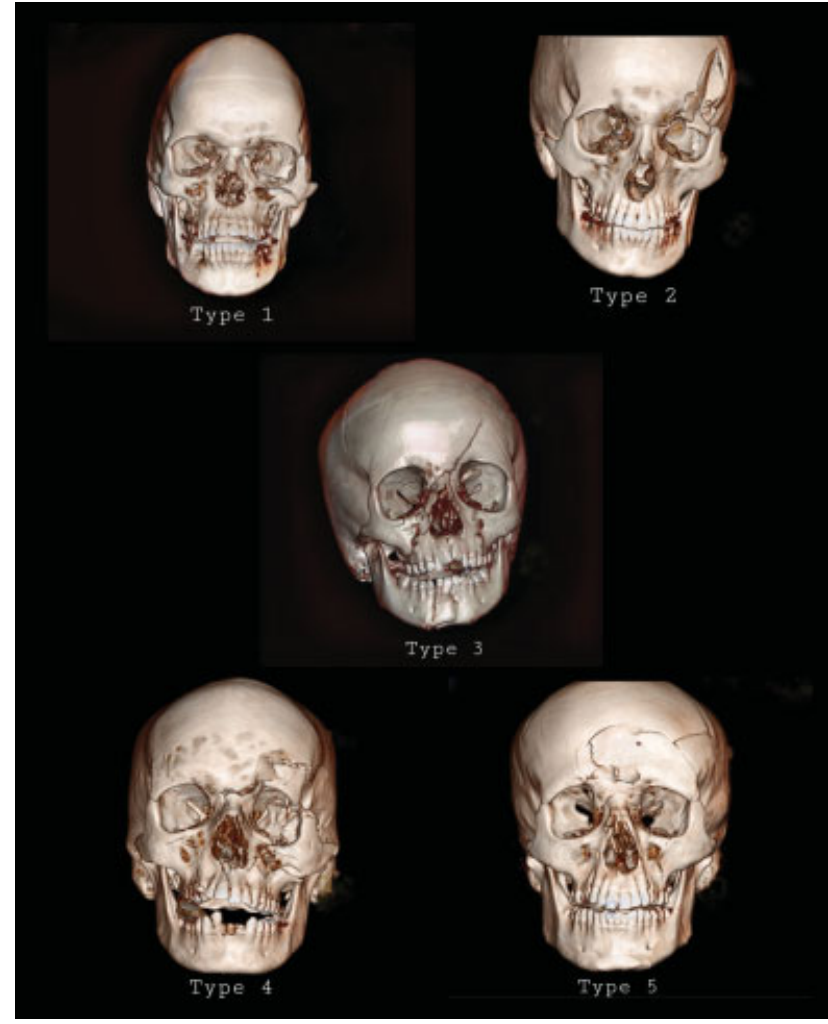

Fig. 2 Computed tomography of brain bone window: Patients with frontal bone fractures, nonvertical fracture-Type 1 and vertical fractures Type 2-5. Type 2 fracture shown with involvement of the orbit but not the frontal sinus. Type 3 fracture depicted with involvement of the frontal sinus but not the orbit. Type 4 fracture involves the ipsilateral right frontal sinus and orbit. Type 5 fracture involves the right frontal sinus and extends inferiorly into the bilateral orbits.

sinus. These fractures were exposed either via an existing laceration or with a bicoronal flap. Intraoperatively, the patency of the NFD was confirmed. The outer table was reconstructed with titanium plates and screws. Displaced inner table fractures and/or outer table fractures associated with intracranial injuries (subdural hematoma/extradural hematoma/intraparenchymal contusion) requiring surgical evacuation and cases with CSF leak underwent bicoronal craniotomy, with removal of the sinus mucosa and the frontal sinus was packed with muscle/Gelfoam and bone wax/methyl methacrylate bone cement and cranialization done with pericranial fascia (-Fig. 5). The anterior cranial floor was lined with pericranial flap and tissue glue was applied. Lumbar drain was placed after the surgical procedure in those cases with preoperative CSF rhinorrhea and was removed on the 5th postoperative day. A repeat CT scan of the brain was done for all patients who underwent cranialization 12 hours postsurgery. In the postoperative period, clinical parameters like GCS score, CSF leak, clinical features of meningitis, and other complications were recorded.

Statistical analysis was done using chi-squared test to analyze our data and validate the modified grading system using SPSS Inc. Version 18.0 software (released 2009. PASW

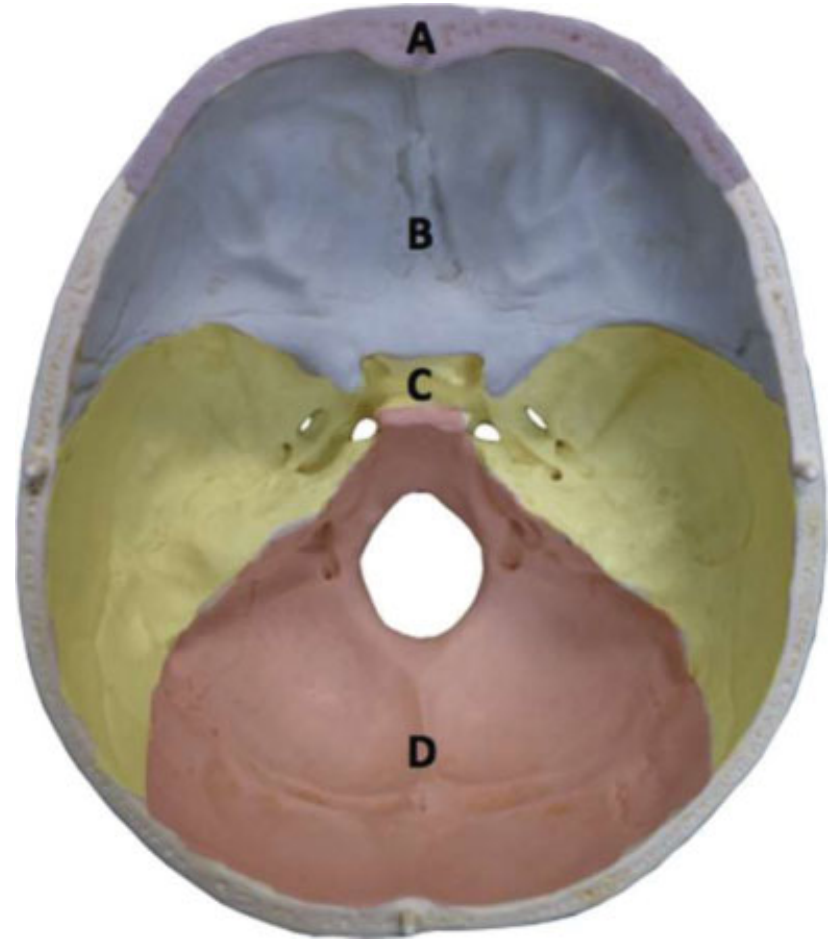

Fig. 3 Illustrative figure: Skull base penetration: Depth A fractures involve the anterior table of the frontal bone with or without posterior table involvement and do not extend into the anterior cranial fossa (purple). Depth B fractures involve the floor of the anterior cranial fossa (blue). Depth C fractures involve the middle cranial fossa (yellow). Depth $D$ fractures extend into the posterior cranial fossa (red). Image courtesy: Garg et al. ${ }^{8}$

Statistics for Windows, Version 18.0, SPSS Inc., Chicago, IL, United States). Whenever chi-square assumptions failed, rows and columns were combined and the data was analyzed. $p$-Value of $\leq 0.05$ was considered statistically significant.

\section{Results}

A total of 85 patients, out of which 24 patients were excluded from the study as no patient has soft tissue findings of black eyes but no documented frontal bone fracture and 6 patients were lost to follow-up. Thus, 55 patients were included into the study. The demographic details, frequency distribution of mechanism of injury, fracture type and depth are shown in - Table 1. The mean age $32.2 \pm 15.72$ years ranged between 7 and 71 years. Isolated outer table of frontal sinus fractures was present in 11 patients and fractures involving both outer and inner table were present in 44 patients. No patient presented with isolated inner table fracture. According to the novel classification by Garg et $a^{8}{ }^{8}$ type 1 fractures were maximally seen in about $34.5 \%$ of patients having type 1 fracture, while type 3 was least recorded in $9 \%$ of patients. With respect to depth of the fracture, type A (45.4\%) and type B 26 (47.2) were most commonly recorded. At the time of presentation, 30 (54.5\%) patients had a mild GCS score 13 to 15,16 (29\%) patients had a moderate GCS score 9 to 12 , and 


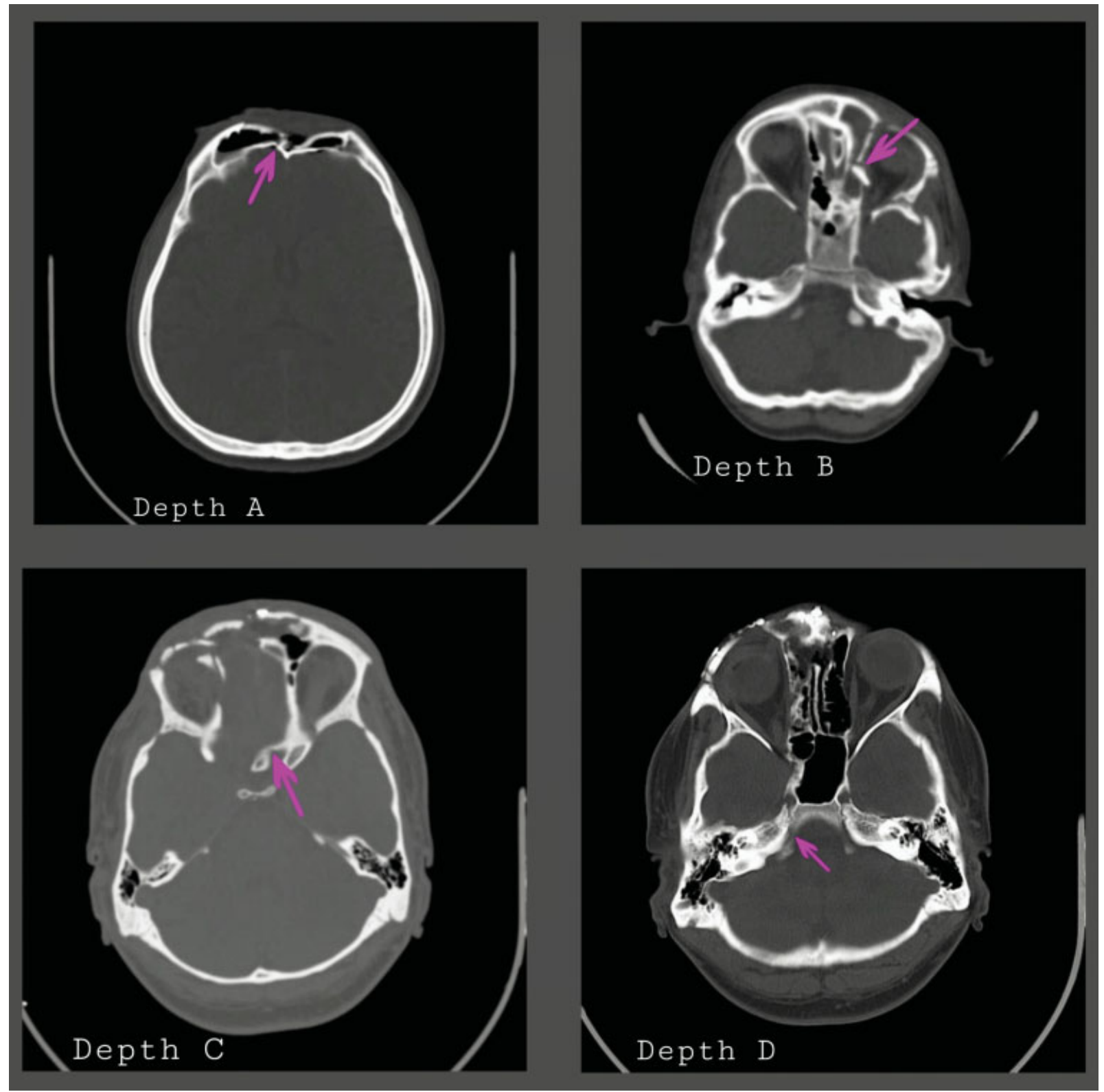

Fig. 4 Computed tomography of brain reconstructive image: Patients with frontal bone fractures and skull base extension. Depth A fracture demonstrated with fracture of anterior and posterior frontal bone tables (pink arrow) but no skull base involvement. Depth B fracture shown with involvement of the fovea ethmoidalis (pink arrows). Depth C fracture shown extending to the fovea ethmoidalis, sphenoid sinus, greater sphenoid wing, and the pituitary fossa (pink arrow). Depth D fracture depicted with extension beyond the clivus (pink arrow) into the foramen magnum.

$9(16.3 \%)$ patients had a severe GCS score $<8$ ( - Table $\mathbf{1})$. Thirty-six patients had associated intracranial injuries that included pneumocephalus $(n=15)$, cerebral contusions $(n=10)$, epidural hematoma $(n=10)$, and subdural hematoma $(n=9)$ (-Table 2). Associated intracranial injuries were seen more commonly with type 4 and 5 fractures, which were statistically not significant. At the time of presentation, CSF rhinorrhea was present in four patients, out of which three patients had type 5 and one patient had type 1 (no statistical significance) and two patients had depth B, one each with depth C and D. CSF rhinorrhea was associated more with fracture extension to the skull base (depths B, C, D) that was statistically significant $(p<0.001)$
(-Table 3). Concomitant maxillofacial fractures were present in all the patients that included nasoorbitoethmoidal $(n=29)$, Lefort III $(n=10)$, Lefort II $(\mathrm{n}=17)$, Lefort I $(n=10)$, zygomaticomaxillary complex $(n=15)$, nasal bones $(n=15)$, orbital $(n=8)$, and mandible fractures $(n=12)$.

Among 11 patients with outer table involvement only, 9 were managed conservatively and 2 patients with displaced outer table fractures of the frontal sinus where the bony displacement was more than or equal to the width of the outer table with NFD obstruction underwent open reduction and internal fixation (ORIF) with sinus preservation. The outer table was reconstructed with titanium miniplates and screws (1.2 or $2.0 \mathrm{~mm}$ ). Among 55 patients studied, 44 


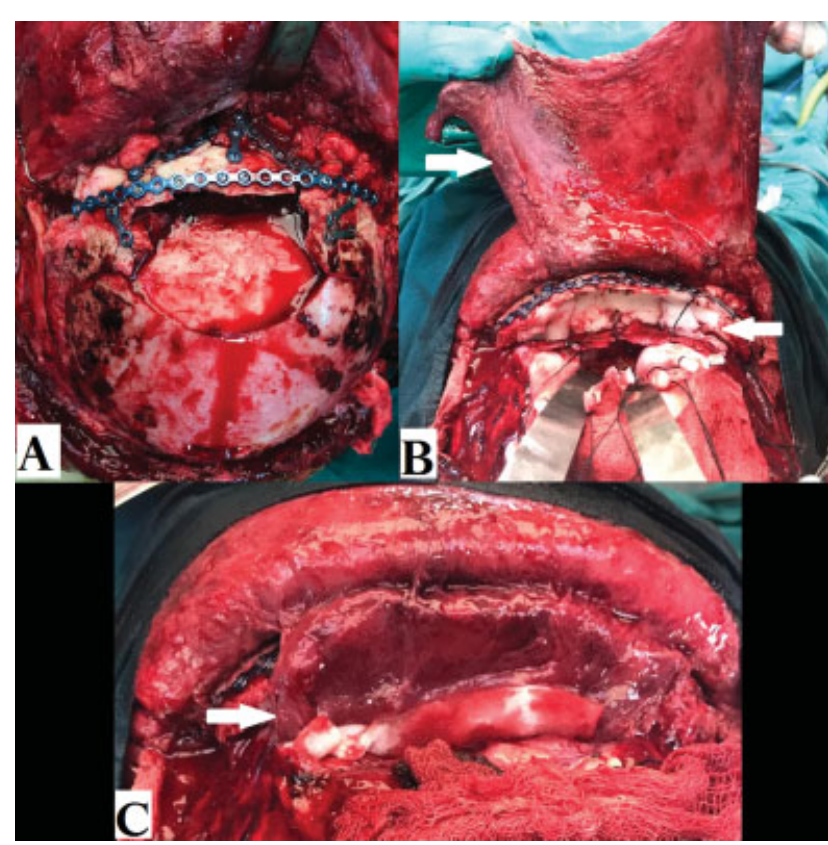

Fig. 5 Intraoperative images: (A) Open reduction and internal fixation of outer table fracture fragments with miniplates, (B) harvested pericranial fascia and obliteration of frontal sinus with bone wax, (C) cranialization with pericranial fascia.

patients with both outer and inner table fractures with associated intracranial injuries requiring surgical evacuation and four patients with associated CSF leak underwent bifrontal craniotomy ORIF with cantilever plate and screw fixation and cranialization (-Table 4).

Postoperative complications were seen in five patients who were treated surgically (-Table $\mathbf{5}$ ). In the immediate postoperative period, two patients developed meningitis and recovered with antibiotics. However, one patient, who was classified as severe clinicoradiological grade, died postoperatively due to septicemia and multiple organ failure. In the follow-up period, one patient developed infection at the incision site which that successfully treated with local debridement and antibiotics. Two patients who were treated surgically for outer and inner table fontal sinus fractures
Table 1 Patient demographic details and fracture characteristics

\begin{tabular}{|c|c|}
\hline Sex & $\begin{array}{l}\text { Number of } \\
\text { patients }(n)(\%)\end{array}$ \\
\hline Male & $49(89)$ \\
\hline Female & $6(11)$ \\
\hline \multicolumn{2}{|l|}{ Mechanism of injury } \\
\hline RTA & 50 (90.9) \\
\hline Assault & $3(5.5)$ \\
\hline Self-fall & $1(1.8)$ \\
\hline Sports & $1(1.8)$ \\
\hline \multicolumn{2}{|c|}{ Frontal sinus fracture location } \\
\hline Outer table & $11(20)$ \\
\hline Outer + inner table & $44(80)$ \\
\hline Inner table & - \\
\hline \multicolumn{2}{|l|}{ Fracture type } \\
\hline 1 & $19(34.6)$ \\
\hline 2 & $10(18.2)$ \\
\hline 3 & $5(9.1)$ \\
\hline 4 & $7(12.7)$ \\
\hline 5 & $14(25.5)$ \\
\hline \multicolumn{2}{|l|}{ Fracture depth } \\
\hline A & $25(45.5)$ \\
\hline B & $26(47.3)$ \\
\hline $\mathrm{C}$ & $3(5.5)$ \\
\hline $\mathrm{D}$ & $1(1.8)$ \\
\hline \multicolumn{2}{|l|}{ GCS score } \\
\hline Mild & $30(54.5)$ \\
\hline Moderate & $16(29)$ \\
\hline Severe & $9(16.3)$ \\
\hline
\end{tabular}

Abbreviations: GCS, Glasgow Coma Scale; RTA, road traffic accident. Type and depth classification based on Garg et al ${ }^{8}$ as described in -Fig. 1.

Table 2 Intracranial injury associated with fracture type and depth

\begin{tabular}{|l|l|l|l|l|l|l|}
\hline \multicolumn{2}{|l|}{ Intracranial injuries } & No injury & Pneumocephalus & Contusion & Epidural hemorrhage & Subdural hemorrhage \\
\hline \multirow{5}{*}{ Fracture type } & Type 1 & 11 & 7 & 1 & 1 & 1 \\
\cline { 2 - 7 } & Type 2 & 5 & 2 & 3 & - & 2 \\
\cline { 2 - 7 } & Type 3 & 1 & - & - & 2 & 2 \\
\cline { 2 - 7 } & Type 4 & 2 & 3 & 2 & 1 & - \\
\cline { 2 - 7 } & Type 5 & - & 3 & 4 & 6 & 4 \\
\hline \multirow{5}{*}{ Fracture depth } & A & 19 & 4 & 3 & 1 & - \\
\cline { 2 - 7 } & B & - & 11 & 6 & 6 & 7 \\
\cline { 2 - 7 } & C & - & - & - & 3 & 1 \\
\cline { 2 - 7 } & D & - & - & 1 & - & 1 \\
\hline
\end{tabular}

Note: The values indicate the number of cases. Type and depth based on Garg et al, ${ }^{8}$ described in - Table 1 note. 
Table 3 Frequency of distribution of subjects based on type and depth with CSF leak

\begin{tabular}{|c|c|c|c|c|}
\hline \multirow[t]{2}{*}{ Type } & \multicolumn{2}{|l|}{ CSF leak } & \multirow[t]{2}{*}{ Total } & \multirow[t]{2}{*}{$p$-Value } \\
\hline & Present, $n(\%)$ & Absent, $n(\%)$ & & \\
\hline 1 & $1(5.3)$ & $18(94.7)$ & $19(100)$ & \multirow{5}{*}{$\begin{array}{l}\text { Chi-square =5.999, } \\
\mathrm{df}=1 \\
p<0.199\end{array}$} \\
\hline 2 & 0 & $10(100)$ & $10(100)$ & \\
\hline 3 & 0 & $4(100)$ & $4(100)$ & \\
\hline 4 & 0 & $8(100)$ & $8(100)$ & \\
\hline 5 & $3(21.4)$ & $11(78.6)$ & $14(100)$ & \\
\hline \multirow[t]{2}{*}{ Depth } & CSF leak & & Total & \multirow{7}{*}{$\begin{array}{l}\text { Chi-square }=17.739 \\
\mathrm{df}=1 \\
p<0.001\end{array}$} \\
\hline & Present,n (\%) & Absent,n (\%) & & \\
\hline A & 0 & $25(100)$ & $25(100)$ & \\
\hline B & $2(7.7)$ & $24(92.3)$ & $26(100)$ & \\
\hline C & $1(33.3)$ & $2(66.7)$ & $3(100)$ & \\
\hline $\mathrm{D}$ & $1(100)$ & 0 & $1(100)$ & \\
\hline Total & $4(7.3)$ & $51(92.7)$ & $55(100)$ & \\
\hline
\end{tabular}

Abbreviation: CSF, cerebrospinal fluid.

Note: Type, grade, and depth based on Garg et al, ${ }^{8}$ described in - Table 1 note.

Table 4 Treatment

\begin{tabular}{|l|l|}
\hline Treatment & No. of Patients $(\boldsymbol{n})$ \\
\hline Conservative & 9 \\
\hline ORIF with sinus preservation & 2 \\
\hline ORIF + cranialization & 44 \\
\hline
\end{tabular}

Abbreviation: ORIF, open reduction and internal fixation.

Cranialization-anterior cranial floor is repaired with vascularized pericranial flap, after obliteration of frontal sinus with bone cement.

developed contour defects but refused secondary surgery. All the other patients had good surgical outcome over the follow-up period of 1 year.

\section{Discussion}

In this retrospective study, 55 frontal bone fracture patients were clinically and radiologically assessed based on Garg et al classification ${ }^{8}$ that was purely a radiologic type of classification. The patients were surgically treated specifically based on their clinical presentation, GCS score, and CT finding with significant intracranial injuries with mass effect requiring craniotomy and evacuation based on presence or absence of CSF leak. Those patients with only outer table fracture were mostly managed conservatively. It was observed that all patients treated in this study had a good surgical outcome. In the current study, $90 \%(n=50)$ of the cases were due to RTA followed by assaults in $5.4 \%(n=3)$ of the cases. Garg et al reported RTA as commonest mechanism of injury in $65.1 \%$ of the cases. In the present study, based on Garg et al, radiological classification, type 1 and depth $B$ were the most common variety seen. CSF rhinorrhea was seen in depth B, C, and D that is statistically significant. Intracranial injuries were more common in type 5 fractures followed by type 1 . Pneumo-
Table 5 Complications in the surgical group

\begin{tabular}{|l|l|}
\hline Complications & No. of patients $(\boldsymbol{n})$ \\
\hline Contour defect & 2 \\
\hline Wound infection & 1 \\
\hline Meningitis & 2 \\
\hline Death & 1 \\
\hline
\end{tabular}

cephalus was more commonly seen in depth B. Garg et al reported commonest type of fracture as type $1(n=51)$, followed by type $5(n=38)$ and fracture depth type B ( $n=66)$, followed by type $\mathrm{D}(n=35)$ to be the most common. Intracranial injuries were reported in $65.8 \%$ of cases in the study conducted by Garg et al and were more common in type 4,5 , and CSF leak was more common in depth B, C, and D.

Majority of outer table fractures only were managed conservatively in our study except two cases, where NFD obliteration was noticed, were managed with ORIF and NFD preservation. Bell et $\mathrm{al}^{7}$ advocate the preservation of sinus function whenever possible, which is generally indicated for patients with displaced outer table fractures, no NFD involvement, and minimal or no posterior table disruption. The NFD is located posteromedial within the sinus and is susceptible to injury in one-third of the frontal bone fractures. ${ }^{9-12}$

In our study, all patients with inner table involvement had significant intracranial injuries requiring craniotomy and evacuation and four of the patients had CSF leak and hence they underwent bifrontal craniotomy, ORIF, and cranialization with pericranial fascia. Cribriform plate where the dura is densely adherent and the foveae ethmoidalis where the bone is thinnest and sometimes dehiscent are the two most common regions if fracture results in CSF leak. ${ }^{10,13-16}$ It is important to note that depth $\mathrm{B}$ and $\mathrm{C}$ have higher chance of 
CSF rhinorrhea. Depth B and C are often associated with higher frequency of intracranial injuries that results in brain edema, which may mask CSF rhinorrhea that usually manifests once the brain edema subsides (4- or 5-day postinjury). It is difficult to assess CSF rhinorrhea in unconscious patients with poor GCS.

Management of patients with posterior table fracture with CSF rhinorrhea is a controversy, where some advocate early surgical intervention to prevent meningitis ${ }^{17}$, while some advocate observation and conservative management with the hope of spontaneous resolution of CSF leak ${ }^{18}$ In our institute, we prefer early surgical intervention for CSF leak in the form of obliteration of sinus and cranialization.

Five patients had postoperative complications in our series, in which four were managed conservatively and recovered. All the remaining patients had a good surgical outcome over a follow-up duration of 1 year.

Decision when to operate and when to conserve is purely based on clinical presentation of the patient and the treating clinicians experience. In most centers, patients presenting with CSF leak or frontal bone fractures with intracranial hematomas with midline shift requiring surgical evacuation are considered as indication for surgery.

\section{Conclusion}

The management of frontal sinus fractures depends on the site and extent of injury. Fracture depth B, C, and D usually have fracture line running along the skull base and require significant force to produce and such fractures are usually associated with dural and intracranial injuries and CSF leak requiring surgery in the form of cranialization. Maxillofacial injuries also play an important role in treatment planning.

\section{Funding}

None.

\section{Conflict of Interest}

None declared.

\section{References}

1 Ravindra VM, Neil JA, Shah LM, Schmidt RH, Bisson EF. Surgical management of traumatic frontal sinus fractures: case series from a single institution and literature review. Surg Neurol Int 2015; 6:141. Doi: 10.4103/2152-7806.163449

2 Metzinger SE, Metzinger RC. Complications of frontal sinus fractures. Craniomaxillofac Trauma Reconstr 2009;2(01):27-34

3 Jeyaraj P. Frontal bone fractures and frontal sinus injuries: treatment paradigms. Ann Maxillofac Surg 2019;9(02):261-282

4 Maladière E, Bado F, Meningaud JP, Guilbert F, Bertrand JC. Aetiology and incidence of facial fractures sustained during sports: a prospective study of 140 patients. Int J Oral Maxillofac Surg 2001;30(04):291-295

5 Strong EB. Frontal sinus fractures: current concepts. Craniomaxillofac Trauma Reconstr 2009;2(03):161-175

6 Doonquah L, Brown P, Mullings W. Management of frontal sinus fractures. Oral Maxillofac Surg Clin North Am 2012;24(02):265-274 , ix

7 Bell RB, Dierks EJ, Brar P, Potter JK, Potter BE. A protocol for the management of frontal sinus fractures emphasizing sinus preservation. J Oral Maxillofac Surg 2007;65(05):825-839

8 Garg RK, Afifi AM, Gassner J, et al. A novel classification of frontal bone fractures: the prognostic significance of vertical fracture trajectory and skull base extension. J Plast Reconstr Aesthet Surg 2015;68(05):645-653

9 Heller EM, Jacobs JB, Holliday RA. Evaluation of the frontonasal duct in frontal sinus fractures. Head Neck 1989;11(01):46-50

10 Rice DH. Management of frontal sinus fractures. Curr Opin Otolaryngol Head Neck Surg 2004;12(01):46-48

11 Rohrich RJ, Mickel TJ. Frontal sinus obliteration: in search of the ideal autogenous material. Plast Reconstr Surg 1995;95(03): 580-585

12 Nelson EL, Melton LJ III, Annegers JF, Laws ER, Offord KP. Incidence of skull fractures in Olmsted County, Minnesota. Neurosurgery 1984;15(03):318-324

13 Samii M, Tatagiba M. Skull base trauma: diagnosis and management. Neurol Res 2002;24(02):147-156

14 Luce EA, Tubb TD, Moore AM. Review of 1,000 major facial fractures and associated injuries. Plast Reconstr Surg 1979;63 (01):26-30

15 Gentry LR. Facial trauma and associated brain damage. Radiol Clin North Am 1989;27(02):435-446

16 Manson PN, Stanwix MG, Yaremchuk MJ, Nam AJ, Hui-Chou H Rodriguez ED. Frontobasal fractures: anatomical classification and clinical significance. Plast Reconstr Surg 2009;124(06): 2096-2106

17 Gossman DG, Archer SM, Arosarena O. Management of frontal sinus fractures: a review of 96 cases. Laryngoscope 2006;116(08): 1357-1362

18 Choi M, Li Y, Shapiro SA, Havlik RJ, Flores RL. A 10-year review of frontal sinus fractures: clinical outcomes of conservative management of posterior table fractures. Plast Reconstr Surg 2012; 130(02):399-406 